\title{
Extended Endonasal Solo Endoscopic Approach for the Resection of Craniopharyngiomas
}

\author{
SAMSULALAM ${ }^{1}$, AN WAKIL UDDIN ${ }^{2}$, ANIS AHMED ${ }^{3}$, MOSHIUR RAHMAN MOJUMDER $^{4}$, \\ KAMRUNNESSA HOSSAIN ${ }^{5}$, ASM ABU OBAIDA ${ }^{2}$
}

\begin{abstract}
:
Background: Extended endonasal solo endoscopic approach for the non-pituitary lesions of the sellar and suprasellar regions are not new in the field of neurosurgery. Following endoscopic surgical approach of the pituitary adenoma, endoscopic neurosurgeon is eager to develop the skill for non-pituitary sellar \& suprasellar lesions. Common sellar \& suprasellar lesions are pituitary adenoma, craniopharyngioma, tuberculumselle meningioma and suprasellar germinoma. Objective: Traditional transsphenoidal approach gives exposure to the pituitary fossa, whereas extended approach provides exposure to the optic nerve, chiasm, acom complex and basal frontal lobe ,mammillary body, mid brain and laterally to the cavernous sinuses. Material \& method: From November 2007 to March 2012, 12 cases of done by extended endonasal solo endoscopic approach among 12 cases of craniopharyngiomas. Patient's history, clinical findings, pre-operative and post-operative visual acuity, visual field and radiological data were collected and analyzed. All patients underwent solo endoscopic extended transsphenoidal approach with or without nasoseptal flap technique for closure. Most of the patients were given lumbar drain as a treatment for CSF leak. Result: All patients were of age group of 10 to 60 years. Male were 8 (66.67\%), female were 4 (33.33\%) in number. Gross total removals were done in 7 cases out of 12 (58.33\%) craniopharyngiomas and subtotal removal done in 5 $(41.67 \%)$ cases. Visual acuity and field of vision were improved in all cases of craniopharyngiomas. One case (8.33\%) of craniopharyngioma had prolong period of unconsciousness probably from hypothalamic disturbance. CSF leak developed in 2 (16.67\%) cases. Patients with craniopharyngioma were required thyroxin and cortisol for replacement. Permanent diabetes insipidus developed in 5 cases (41.67\%). Three patients required permanent CSF diversion via a ventriculoperitoneal shunt after documentation of postoperative HCP. There was one case of chemical meningitis, and two cases confirmed bacterial infections. Craniopharyngioma can be successfully resected via a purely endoscopic, endonasal approach. Craniopharyngioma have a higher rate of perioperative hydrocephalus and postoperative CSF leak compared with other tumor types in the same area. Conclusion: Extended transsphenoidal approach is an excellent alternative of skull base approach for the removal of most of the craniopharyngioma. The endoscopic endonasal route provides a good exposure, especially of the sub-chiasmatic and retro-chiasmatic areas, as well as of the stalkinfundibulum axis and the third ventricle chamber. It gives better visualization, improved postoperative visual outcome for less manipulation and low complication then craniotomy. However CSF leak and diabetes insipidus is common known complications which have to be manage promptly and appropriately.
\end{abstract}

Abbreviation: CSF (cerebrospinal fluid), D I (diabetis insipidus), HCP(hydrocephalus)

Introduction:

Craniopharyngioma is a benign epithelial tumors of the seller region but can have significant neurological and endocrinological consequences and may require treatment that will cause further morbidity ${ }^{1}$. As craniopharyngioma grow, it can cause significant

1. Assistant Professor, Department of Neurosurgery, Bangabandhu Sheikh Mujib Medical University, Dhaka.

2. Research Assistant, Department of Neurosurgery, Bangabandhu Sheikh Mujib Medical University, Dhaka.

3. Resident, Department of Neurosurgery, Bangabandhu Sheikh Mujib Medical University, Dhaka.

4. Registrar, Department of Neurosurgery, Comilla Medical College, Comilla.

5. Consultant, Department of Radiology, Popular Diagnostic Centre, Dhaka. 
neurological complications, including visual loss, pituitary insufficiency, and hypothalamic damage, and recurrence following surgery. The first description of a craniopharyngioma was credited to Zenker, who made this observation in $1857^{1,2}$. Following this, Mott and Barrett, in 1899, documented the occurrence of these tumors and postulated that they arose from the hypophyseal duct or Rathke pouch ${ }^{3}$. This was subsequently partially confirmed in 1904, when Erdheim described the tumors histologically and suggested that they arose from remnants of the Rathke duct ${ }^{3,4}$. Finally, in 1932, Cushing introduced the term "craniopharyngioma," which has been widely used thereafter.

The incidence of newly diagnosed craniopharyngioma is 0.13 to 2.0 persons per 100,000 population per year. Distribution by age is bimodal, with the peak incidence in children in between 5-14 years and in adults in between 50-75 years ${ }^{5}$. Craniopharyngioma account for $1-3 \%$ of all brain tumors, and half of these tumors occur in childhood. Craniopharyngioma account for $5-10 \%$ of brain tumors in children.No sex predilection exists, and they equally occur in males and females ${ }^{5,6}$.

The clinical presentation can include a wide range of symptoms, which depend on the location of the tumor and involvement of adjacent structures ${ }^{7}$. Headache is the most common presenting symptom, followed by endocrine deficiencies and visual disturbances. Headache is usually due to either the tumor's mass effect or hydrocephalus (from obstruction of the foramen of Monro, third ventricle, or aqueduct of Sylvius), which occurs in $15-30 \%$ of patients ${ }^{6,7}$.

Endocrine disturbances are related to direct compression from the tumor. Of the endocrine deficiencies, the most common is growth hormone (75\%), followed by gonadotropin (40\%), thyroidstimulating hormone (25\%), and corticotropin (25\%) hormones. Growth failure can be seen in up to $93 \%$ of children with craniopharyngioma and is related to either growth hormone deficiency, hypothyroidism, or both. Adults have more varied presentation and may develop sexual or menstrual dysfunction. Eighty-eight percent of men experience decreased sex drive, while $82 \%$ of women have amenorrhea. Other endocrine dysfunction may lead to precocious puberty and obesity ${ }^{8}$.

Large tumors in adults can cause psychiatric symptoms, memory loss, apathy, incontinence, depression, and hypersomnia. Long-standing cognitive deficits and profound memory loss have been reported and suggest a worse prognosis. Visual deficits are caused by compression of the optic chiasm from supraseller tumor growth. Classically, the tumor presents as a Bitemporal hemianopia, but it may also manifest as homonymous hemianopia, scotoma, papilloedema or optic atrophy ${ }^{9}$.

Craniopharyngioma surgically divided into 3 groups: seller, prechiasmatic, and retrochiasmatic. Sellerlocated tumors may be supraseller (75\%), infraseller $(21 \%)$, or intraseller $(4 \%)$. According to the grade of involvement of the third ventricle, we identified three main ventricular growth patterns: (1) stalkinfundibulum; (2) infundibulum-ventricular chamber; (3) stalk-infundibulum-ventricular chamber. These tumors occasionally grow into the third ventricle, causing hydrocephalus ${ }^{10,11}$.

The classification scheme divides tumors according to their supraseller extension: Type I is preinfundibular; Type II is transinfundibular (extending into the stalk); Type III is retroinfundibular, extending behind the gland and stalk, and has 2 subdivisions (IIla, extending into the third ventricle; and IIIb, extending into the interpeduncular cistern); and Type IV is isolated to the third ventricle and/or optic recess and is not accessible via an endonasal approach ${ }^{11,12}$.

The arterial supply is usually from the anterior cerebral and anterior communicating arteries or from the internal carotid and posterior communicating arteries $^{12}$.A craniopharyngioma does not receive blood supply from the posterior circulation, unless it is parasitized from the floor of the third ventricle. As these tumors enlarge, they may elevate and infiltrate the optic chiasm as well as the hypothalamic region. Occasionally, they extend into the pituitary fossa or posteriorly to the ventral pons, and, rarely, they invade the basal ganglia or the brain parenchyma ${ }^{13}$. When predominantly in the sella, these tumors erode the bony floor and enlarge the sella. 


\section{Methods:}

From November 2007 to March 2013, 12 cases of done by extended endonasal solo endoscopic approach among 12 cases of craniopharyngiomas. Patient's history, clinical findings, pre-operative and post-operative visual acuity, visual field and radiological data were collected and analyzed. All patients underwent solo endoscopic extended transsphenoidal approach with or without nasoseptal flap technique for closure. Most of the patients were given lumbar drain as a treatment for CSF leak.

\section{Results:}

There were 12 patients retrospectively. Among them 8 patients were male, 4 were females. Age of the patients ranged from 10 years to 60 years, with a mean age of 34.5 years.

All the patients complained of headache and vomiting. Anosmia and personality or behavioral changes were the next common manifestations. Visual impairment was found in 8 cases $(66.67 \%)$ associated with primary optic ataphy.All patients underwent preoperative and postoperative CT scan and/ or MRI of brain. Maximum tumor diameter was $4.5 \mathrm{~cm}$ and mean diameter was $3.42 \mathrm{~cm}$.

Retrochaismaticcraniopharyngioma in 6 patients $(50.00 \%)$, subchaismatic in 3 patients $(25.00 \%)$ andPrechaismatic in 1 patient $(8.33 \%)$, Pre and Retrochaismatic in 2 patients (16.67\%) (Table-I).In all the cases surgery was performed with the help of endoscopic endonasal instrumentation.

Table-I

Types of Craniopharyngioma

\begin{tabular}{llcc}
\hline Name of disease & \multicolumn{3}{c}{$\begin{array}{c}\text { Number } \\
\text { of Cases }\end{array}$} \\
\hline Craniopharyngioma & Retrochaismatic & 6 & $50.00 \%$ \\
& Sub chaismatic & 3 & $25.00 \%$ \\
& Prechaismatic & 1 & $8.33 \%$ \\
& Pre and Retrochais- & 2 & $16.67 \%$ \\
& matic & & \\
\hline Total & & 12 & $100 \%$ \\
\hline
\end{tabular}

Extent of Resection: Extent of resection was determined using pre-operative and postoperativevolumetric analysis of CT scanimages. The comparison was performed by chief surgeon. Evaluation of the series has shown that 7 (58.33\%) of the 12 patients underwent at least gross-total resection(Table-II). Five cases $(41.67 \%)$ of the patients underwent sub-total. All the twelve patients were followed-upwith early postoperative CT scan (Figure 1(a,b,c,d)) and neurological evaluation.

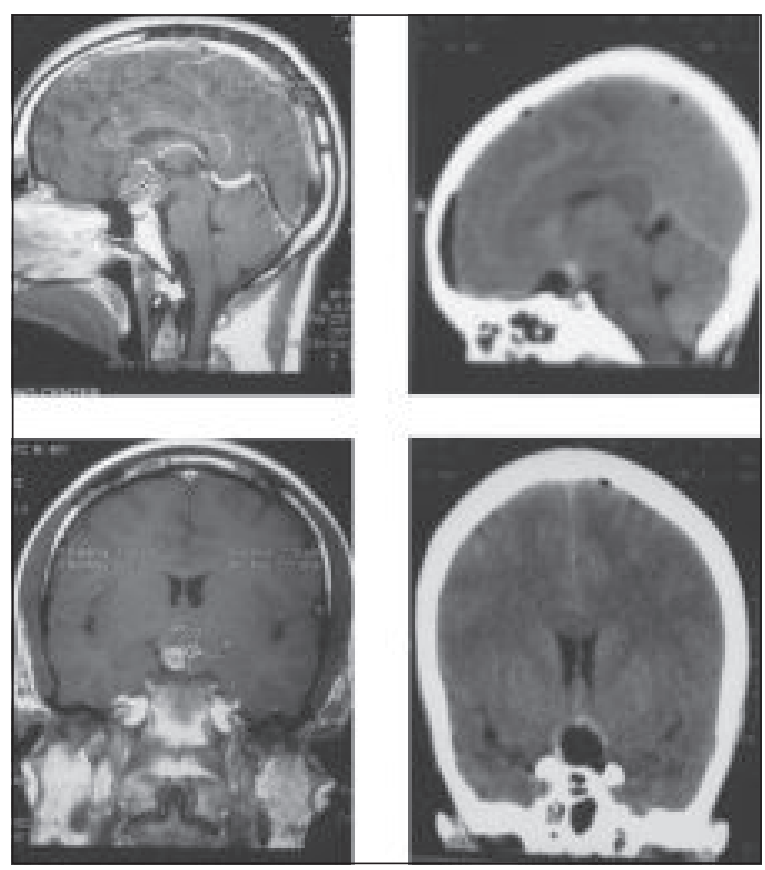

Fig.-1: (a) suprasellercraniopharyngioma(pre op), (b) suprasellercraniopharyngioma(post op), (c) suprasellercraniopharyngioma(pre op), (d) suprasellercraniopharyngioma (post op).

The follow up period ranged from 7 month to 16 months. No recurrence of tumor was found within this short period of follow up. CSF leak was found in two cases. There is no mortality in twelve cases. Two patients developed meningitis among them one patient developed CSF rhinorrhea along with meningitis. This patient was treated by antibiotic therapy and lumbar drain for CSF leak. Small subdural hygroma was developed in one case and small amount of tumor bed hematoma was seen in one case which resolved over time as was evidenced in later scan. Steven Johnson's syndrome was developed in one case following phenytoin therapy. Outcome was good having GOS 5 in 8 patients (66.67\%), GOS 4 in 3 patients (25\%) and GOS 3 in 1 (8.33\%) patient during the follow up period (Table-II). 
Table-II

Shows size, Extent of tumour removal, complication and outcome of craniopharyngioma.

\begin{tabular}{|c|c|c|c|c|}
\hline $\begin{array}{l}\text { No. of } \\
\text { Cases } \\
\end{array}$ & Size of tumour & $\begin{array}{l}\text { Extent of tumour } \\
\text { removal }\end{array}$ & Complications & Outcome \\
\hline 1. & $3 \times 2 \times 3 \mathrm{~cm}$ & Gross total & Permanent DI, Confusion,Dependent feeding & GOS 3 \\
\hline 2. & $4 \times 3 \times 4 \mathrm{~cm}$ & Gross total & Permanent DI , Food refusal & GOS 4 \\
\hline 3. & $4 \times 3 \times 4 \mathrm{~cm}$ & Gross total & $\begin{array}{l}\text { Confusion, Irrelevant talkVP Shunt, Surgery } \\
\text { done for hydrocephalus }\end{array}$ & GOS 5 \\
\hline 4. & $2.5 \times 3 \times 4 \mathrm{~cm}$ & Sub Total & Permanent DI & GOS 5 \\
\hline 5. & $3 \times 3 \times 3 \mathrm{~cm}$ & Gross total & NIL & GOS 5 \\
\hline 6. & $4 \times 3 \times 3 \mathrm{~cm}$ & Gross total & C.S.F. leak & GOS 5 \\
\hline 7. & $4.5 \times 3 \times 3.5 \mathrm{~cm}$ & Sub total & Permanent DI & GOS 5 \\
\hline 8. & $3 \times 3.5 \times 3.5 \mathrm{~cm}$ & Sub total & Hyponatremia & GOS 5 \\
\hline 9. & $2.5 \times 2.5 \times 3 \mathrm{~cm}$ & Sub total & Pneumocephalus & GOS5 \\
\hline 10. & $3 \times 3 \times 3 \mathrm{~cm}$ & Sub total & Tumorbedhaematoma & GOS5 \\
\hline 11. & $3 \times 3 \times 3 \mathrm{~cm}$ & Gross total & C.S.F. leak & GOS 4 \\
\hline 12 & $2.5 \times 2 \times 3 \mathrm{~cm}$ & Gross total & Permanent $\mathrm{DI}$ & GOS 4 \\
\hline
\end{tabular}

Postop visual outcome: Visual improvement was satisfactory. Postoperative visual acuity and visual field were improved in 8 cases $(66.67 \%)$ (Table-III)(Figure 2 \& Figure 3). The visual outcome (for both acuity and fields) was better in younger patients and those with a shorter duration of symptoms. Patients with lesser degrees of
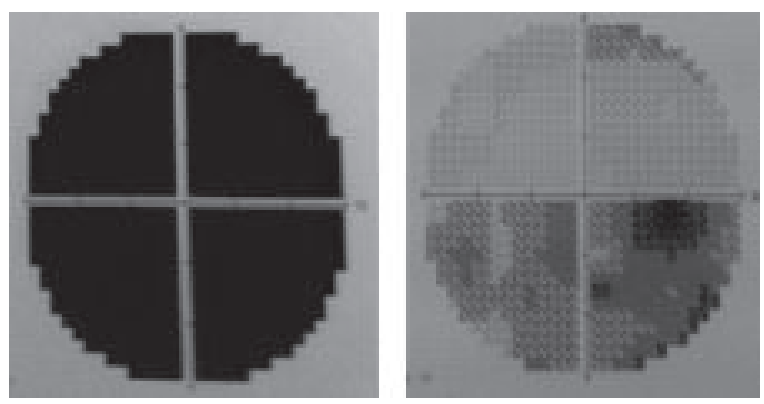

Fig.-2: Pre op (A) and Post op (B) picture of visual field of right eye showing significant improvement. preoperative visual acuity compromise had better postoperative visual acuity outcome. However, the severity of preoperative visual field defects did not seem to predict postoperative field outcome, and even patients with severe preoperative field defects often had striking postoperative improvement.
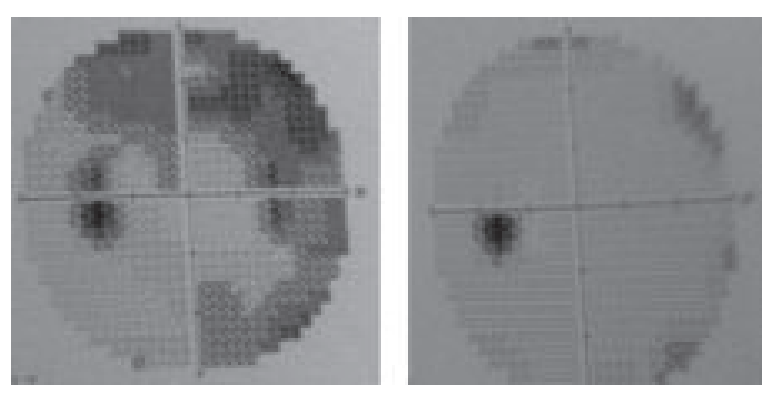

Fig.-3: Pre op (A) and Post op (B) picture of visual field of left eye showing significant improvement. 
Table-III

Preoperative \& Postoperative Visual Status

\begin{tabular}{lccccc}
\hline $\begin{array}{l}\text { Pre-operative } \\
\text { Visual status }\end{array}$ & $\begin{array}{c}\text { No. of } \\
\text { Cases }\end{array}$ & Percent & $\begin{array}{c}\text { Post-operative } \\
\text { Visual status }\end{array}$ & No. of Cases & Percent \\
\hline Bi temporal field defect & 4 & $33.33 \%$ & Improved & 8 & $66.67 \%$ \\
$\begin{array}{l}\text { Unilateral blindness and } \\
\begin{array}{l}\text { Contra lateral temporal } \\
\text { field defect }\end{array}\end{array}$ & 6 & $50.00 \%$ & Not improved/Static & 2 & $16.67 \%$ \\
\begin{tabular}{l} 
Bilateral blindness \\
\hline Total
\end{tabular} & 2 & $16.67 \%$ & Deteriorated & 2 & $16.66 \%$ \\
\hline
\end{tabular}

\section{Endocrine outcome:}

Preop endocrine presentation: Typical endocrinological findings were hypocortisolism, hypothyroidism and hypogonadism were found in most of the cases.

Postop endocrine outcome: Postoperative anterior pituitary dysfunction improved in 4 cases $(33.33 \%)$ out of 12 cases. There were $100 \%$ cases of temporary $\mathrm{DI}$ and about $5 \%$ cases of permanent $\mathrm{DI}$.

Complications:PermanentDI developed in 5 patients (41.67\%), Pneumocephalus in 3 patient $(25.0 \%)$, Small amount of tumor bed hematoma in 1 patient (8.33\%), Hyponatremia in 4 patients $(33.33 \%)$, Hydrocephalus in 2 patients (16.67\%) for which V$P$ shunt were done.

\section{Discussion:}

The extended transphenoidal approach extends operative exposure beyond the sella by removing the tuberculum sellae and a portion of the planum sphenoidale. The advantages of the extended transphenoidal approach over a traditional craniotomy are the avoidance of frontal or temporal lobe retraction or sylvian fissure dissection and the potential associated brain injury ${ }^{14}$.

Approximately $10 \%$ of all transcranial cranial base procedures result in some form of retraction injury to the brain. However, it has generally been thought that an enlarged sella, secondary to the lesions extension, was required to safely reach a suprasellar lesion through a transphenoidal approach ${ }^{15}$.

In our study all 12 patients underwent a detailed neuroophthalmological examination before and after surgery. Eight (66.67\%) of these patients had complete resolution of their visual defect and 2 (16.66\%) had improvement but not complete resolution. Two patient's deficit deteriorated.

In an international study by Amin B. Kassam et al, showed that all of 16 patients underwent a detailed neuroophthalmological examination before and after surgery ${ }^{10}$. The conditions of 2 patients without preoperative visual deficits were unchanged postoperatively. The remaining 14 patients had progressive visual deficits preoperatively. Six (43\%) of these patients had complete resolution of their visual defect, and seven (50\%) had improvement but not complete resolution. One patient's deficit remained stable. One patient had visual worsening 4 days after surgery secondary to hydrocephalus. His vision improved following the placement of a VP shunt ${ }^{16}$.

In an international publication of endocrinological results of 30 patients of craniopharyngioma (Honegger et al. 1999) treated transcranially developed postoperative diabetes insipidus in $60 \%$ cases, adrenal failure in $53.3 \%$ and hypothyroidism in $36.7 \%$ cases $^{17}$.

Microscope-based removal of purely suprasellar craniopharyngiomas and meningiomas has been associated with a 20 to $33 \%$ rate of CSF leak. For craniopharyngiomas, postoperative rates of $\mathrm{DI}$ and panhypopituitarism occur in roughly $70 \%$ cases. In our study permanent DI developed in 5 cases (41.67\%)out of 12, using the endoscopic endonasal approach $^{18,19}$.

We did gross total resection of 6 cases $(50 \%)$ of the craniopharyngiomas with an overall risk of postoperative CSF leak of 4 cases (33.33\%). 
We found that the visualization provided by the endoscope is outstanding for the extended approach to purely suprasellar pathology. This advantage can potentially minimize the risk of morbidity to vital neurovascular structures and also decrease the risk of CSF leakage because closure is more secure, aided by improved visualization 20,21 .

Despite the minimally invasive approach and the use of the endoscope, these endoscopically treated cases are not without morbidity. However, removal of these lesions using a traditional microscopebased transcranial or transphenoidal route also has a potentially high morbidity and mortality rate. The success of this maneuver requires meticulous closure with dural graft inlay, either fascia lata or Dura-Guard, rigid buttressing with either vomer or a metalplate and the use of sealants, such as fibrin glue 22 .

\section{Conclusion:}

Extended transphenoidal approach is an excellent alternative of skull base approach for the removal of selected group of the craniopharyngioma. The endoscopic endonasal route provides a good exposure, especially of the sub- and retrochiasmatic areas, as well as of the stalkinfundibulum axis, and the third ventricle chamber. It gives better visualization, improved postoperative visual outcome for less manipulation and low complication then craniotomy. However CSF leak, $\mathrm{DI}$ are common known complications which have to manage promptly and appropriately.

\section{References:}

1. Cappabianca P, Frank G, Pasquini E, De Diviitis E, Calbucci F. Extended Endoscopic endonasal transsphenoidal approaches to the suprasellar region, planumsphenoidale and clivus, in De Diviitis E, Cappabianca P (eds): Endoscopic EndonasalTranssphenoidal Surgery. New York, Springer-Verlag/Wien, 2003, 176-88.

2. Cavallo LM, Messina A, Cappabianca P, Esposito F, De Diviitis E,Tschabitscher M: Endoscopic endonasal surgery of the midline skull base: Anatomical study and clinical considerations. Neurosurg Focus 2005; 19(1): E2.
3. Frank G, Sciarretta V, Mazzatenta D, Farneti G, Modugno GC, Pasquini E: Transsphenoidal endoscopic approach in the treatment of Rathke's cleft cyst. Neurosurg 2005; 56: $124-29$.

4. Chakrabarti I, Amar AP, Couldwell W, Weiss $\mathrm{MH}$ : Long-term neurological, visual, and endocrine outcomes following transnasal resection of craniopharyngioma. J Neurosurg 2005; 102: 650-57.

5. De Diviitis E, Cappabianca P, Cavallo MC: Endosopic transsphenoidal approach: Adaptability of the procedure to different sellar lesions.Neurosurg 2002; 51: $699-705$.

6. Dusick JR, Esposito F, Kelly DF, Coha P, DeSalles A, Becker DP et al. The extended direct endonasal transsphenoidal approach for Non adenoma toussuprasellar tumors. J Neurosurg 2005; 102: 832-41.

7. Fahlbusch R, Honegger J, Paulus W, Huk W, Buchfelder M: SurgicalTreatment of craniopharyngiomas: Experience with 168 patients. J Neurosurg 1999; 90: 237-50.

8. Jho HD, Ha HG: Endoscopic endonasal skull base surgery. Part 1-The midline anterior fossa skull base. Min Invas Neurosurg 2004.47:1-8.

9. Kaptain GJ, Vincent DA, Sheehan JP, Laws ERJ: Transsphenoidalapproaches for extracapsular resection of midline suprasellar and anteriorcranial base lesions. Neurosurg 2001.49:94-101.

10. Kassam A, Snyderman CH, Mintz A, Gardner P, Carrau RL: Expandedendonasal approach: The rostrocaudal axis. Part 1.Crista galli to thesella turcica. Neurosurg Focus 2005; 19: E3.

11. Kassam A, Snyderman $\mathrm{CH}$, Mintz A, Gardner P, Carrau RL: Expandedendonasal approach: The rostrocaudal axis. Part II. Posterior clinoids tothe foramen magnum.Neurosurg Focus 2005; 19: E4.

12. Kim J, Choe I, Bak K, Kim C, Kim N, Yang Y: Transsphenoidal Supra diaphragmatic intradural approach. Min Invas Neurosurg 2000; 43:37. 
13. Kitano $M$, Taneda $M$ : Extended transsphenoidal approach with submucosal posterior ethmoidectomy for parasellar tumors. J Neurosurg 2001; 94: 999-1004.

14. Landolt AM, Zachman M: Results of transsphenoidal extirpation ofcraniopharyngioma. Neurosurg 1991; 28 : 410-15.

15. Laufer I, Anand VK, Schwartz TH: Endonasal endoscopic extendedtranssphenoidal, transplanum approach for suprasellar lesions. J Neurosurg 2007; 106: 400-06.

16. Amin B. Kassam: Outcomes following endoscopic, expanded endonasalresection of suprasellarcraniopharyngiomas: a case series.J Neurosurg 2008; 109: 6-16.

17. Honegger J, Buchfelder M, Fahlbusch R: Surgical treatment of craniopharyngiomas: Endocrinologicalresults. J Neurosurg 1999; 90: 251-57.
18. Laws ERJ: Transsphenoidal microsurgery in the management of craniopharyngioma.J Neurosurg 1980; 52: 661-66.

19. Maira G, Anile C, Albanese A, Cabezas D, Pardi F, Vignati A: The roleoftranssphenoidal surgery in the treatment of craniopharyngioma. J Neurosurg 2004; 100: 445- 51.

20. Mason RB, Nieman LK, Doppman JL, Oldfield $\mathrm{EH}$ : Selective excision of adenomas originating in or extending into the pituitary stalk withpreservation of pituitary function. $\mathrm{J}$ Neurosurg 1997; 87: 343-51.

21. Page RB: Craniopharyngioma: Indications for transsphenoidal surgery. Curr Ther Endocrinol Metab 1994; 5: 33-34.

22. Yasargil MG, Curcuc M, Kis M, Siegenthaler G, Teddy PJ, Roth P:Total removal of craniopharyngiomas. Approaches and longterm results in 144 patients.J Neurosurg 1990; 73:3-11. 